\title{
Strength of a Chair Renovated with Additive Production Systems and Reverse Engineering Approach
}

\author{
Güllü Akkas ${ }^{1}$, Tuğba Andac Guzel ${ }^{2}$ \\ ${ }^{1}$ Lecturer Kayseri University, Vocational College, Department of Mechanical and Metal Technologies Kayseri/Turkey gullu.akkas@kayseri.edu.tr \\ ${ }^{2 *}$ Associate Professor, Kayseri University, Vocational College, Department of design, Kayseri/Turkey tugbaandac@kayseri.edu.tr
}

(International Conference on Design, Research and Development (RDCONF) 2021 - 15-18 December 2021)

(DOI: $10.31590 /$ ejosat.1054613)

ATIF/REFERENCE: Akkas G., Andac Guzel T. (2021). Strength of a Chair Renovated with Additive Production Systems and Reverse Engineering Approach. European Journal of Science and Technology, (32), 1150-1155.

\begin{abstract}
Furniture are items that provide convenience and comfort in daily works, and that are present in all areas of life. The furniture renovation process is of great importance for the protection of furniture and the maintenance of furniture's function. Today, this process may include applications involving reverse engineering and additive production systems. The aim of this study is to provide guidance for amateur and professional workers in the field of furniture renovation about the use of reverse engineering approach and additive production systems in this field. In this study, missing details of a plywood chair were scanned with 3D scanners. Point clouds were obtained in STL format. These point clouds were converted into meaningful data and the missing details were printed out with the additive production system. Damaged areas of the chair were repaired with this method. The repaired chair sample and the original chair sample were subjected to static and dynamic strength tests, and the test results obtained from these samples were compared. As a result of these tests, the renovation work was found to be successful.
\end{abstract}

Keywords: Furniture, Renovation, Reverse Engineering Approach and Additive Production Systems

\section{Introduction}

Engineering is the application of mathematics and scientific, economic, social and practical knowledge to discover, develop, design, research, build and improve systems, components, materials, processes, and solutions. Engineering can be studied under two main headings: Forward engineering and reverse engineering. Forward engineering is the classic engineering activities $^{1}$. Classical engineering activities are successive approaches. This may result in deficiencies in some of the processes (such as the lack of CAD models for the product) (SAHIN et al., 2017; THOMPSON et al., 1999). In such cases, moving backwards from the part itself, the process is carried out in backwards. Obtaining the computer-aided design model at the initial stage of the product is called reverse engineering (SAHIN et al., 2017). Reverse engineering is a process in which the structure of a man-made object is taken apart or the object is examined backwards in order to reveal its designs and architecture or to gain information from the object (EILAM, 2011).

Reverse engineering studies can be used to obtain 3D design codes of a product in many fields from aerospace to automotive industry, and from furniture industry to machinery industry. Especially today, the world population is increasing rapidly. In parallel to this, the demand for quality, robust furniture is also increasing. And forest assets, on the other hand, tend to decrease continuously due to these factors. As a result, the use of solid materials in furniture production is becoming less and less economical each day (KASAL, 2007). This issue increases the value of furniture made of wood. Maintenance, repair and renovation are important to slow down the aging of these furniture items and increase their service life.

Renovation means repairing, renewing and restoring. And furniture is the items that provide convenience and comfort for us in sitting, eating, working, sleeping and etc. The term "Furniture Renovation" can be defined as repairing and renewing furniture to preserve its unique properties, and helping it maintain its existence with its existing function or with a new function aimed to be given to it. In the renovation process, all the details of the furniture are examined and a reverse process is initiated to give it a function that is similar to its initial one or a new one. As it can be seen, furniture renovation is a process in its own right that is carried out in reverse by revealing all the details of furniture. The difficulty in capturing the details of hand-made decoration especially in classical furniture with standard renovation techniques brings with it very challenging processes. At this point, using the reverse engineering approach to obtain meaningful data from the existing product for CAD-CAM-CAE processes can yield very practical solutions for products with intricate handcrafted details (Akkas, 2019).

When reverse engineering and additive production systems are considered as a whole, they can produce special solutions for furniture renovation. Today, 3D scanners are actively utilized in reverse engineering activities. (Andac Güzel 2019) and 3D

* Corresponding Author: tugbaandac@kayseri.edu.tr 
printers are the latest technology that makes it possible to reach the final product of complex products that are retrospectively CAD modeled with 3D scanners (Ding et al., 2019) The basic cycle shown in Figure 1 can be a key code for many sectors as well as a process scheme that can be followed in the field of furniture renovation.

\subsection{Literature Review}

In recent years, when the studies in the field of furniture and architecture are examined, they provide insight into the use of reverse engineering and additive production systems. By looking at the current studies, it can be seen that 3D scanners and 3D printers will have an important place in the furniture sector, too. Today, 3D scanning technologies are used in furniture, artworks, interior and many technical fields. Using 3D scanning technologies, Scopigno (2003) has done a study on the creation of 3D digital presentations of Cultural Heritage monuments with very high accuracy and rich in detail. The 3D model of Michelangelo's sculpture 'David' was reconstructed using laserbased 3D scanning technology. According to the results of their studies, it was concluded that $3 \mathrm{D}$ scanning technologies is a useful tool for archiving and integrating all information about restoration (SCOPIGNO et al., 2003). In the mechanical field, in the event of damage or malfunction of the devices or parts, the damaged parts must be replaced with new ones to prevent loss of time and financial damage. Nowadays, there are ongoing studies on various techniques which can produce new parts to replace damaged parts in a very short time. For example, in their study, Dubravcik and Kender (2012) analyzed techniques such as 3D scanning and rapid prototyping that could be used for mechanics and measuring systems services (DUBRAVCIK and KENDER, 2012).

In the field of furniture, Chengmin et al. (2018) obtained three-dimensional data by scanning a complex furniture surface and then converting the scanning data into a common data format to simulate the model of the scanned object (CHENGMIN, 2018). In the field of architecture, Ding et al. (2019) proposed a digital construction system that integrates building information modeling. They have optimized the efficiency of the system renovation process in the renovated shopping center in Hainan, China. 3D laser scanning systems were used in this process (Ding, et al., 2019).

There are several researches on 3D modeling and printing. For example, Kang (2015) conducted a study on furniture design with $3 \mathrm{D}$ printing. He examined the difference in practicality, usability and durability between real furniture design and 3D print furniture design. It was concluded that these issues would be possible in production in small quantities for your personal taste (KANG, 2015). Fondevilla et al. (2017) proposed an interactive tool to model three-dimensional (3D) objects from twodimensional (2D) photographs. With this tool they proposed, they made two-dimensional photographs usable for reverse engineering, and obtained important products especially from the three-dimensional model obtained for symmetrical parts (FONDEVILLA et al., 2017).

Yang et al. (2019) conducted a research on how to apply the handcraft art of pierced wood carving in the furniture field with the help of 3D printers. In their research, they studied the geometric modeling of the carving and the printability of the model obtained, high-quality print resolution and physical stability of the print obtained when compared to the original print. According to the experimental results of the study, they obtained producible and visually satisfactory results (YANG et al., 2019). Andac Guzel (2019) he has done a research on furniture joins produced with the help of 3D printers. As a result of the research, it has determined that the existing studies on furniture joins remain experimental. Emphasized the importance of producing high capacity load bearing furniture with the help of $3 \mathrm{~d}$ printers (ANDAC GUZEL, 2019).

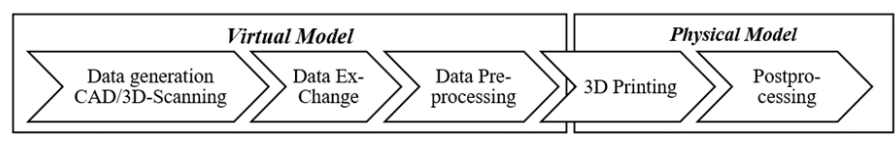

\section{Figure 1 Process Chain from a virtual to a physical model in}

This study aims to provide guidance and an insight about the use of reverse engineering for academic, amateur and professional employees in the field of furniture renovation, which has a significant place in the furniture sector. It also aims to raise awareness on the mechanical behavior of a chair repaired with mechanically reverse engineering and additive production systems.

\section{Materials and Methodology}

In this study, the renovation of a chair made of plywood material was performed. The body of this chair (Figure 1), the legs of which were made of metal, was made of plywood. The legs were connected to round plywood pieces under the seat by means of a plastic apparatus and bolt. These wooden parts were fixed under the seat with a $3.5 \times 13 \mathrm{~mm}$ screw. The round plywood joining apparatus of the chair examined and renovated in the study were in broken or shattered state in the first phase of the study.

In this study, the above mentioned damaged round plywood joining apparatus were re-produced with $3 \mathrm{D}$ printer in the office environment. Three-dimensional (3D) scanners and threedimensional printers were utilized to reproduce these joining apparatus in the office environment. NextEngine brand 3D scanner and Zortrax M200 3D printer were preferred for this study, a part of which was performed in office conditions (NEXTENGINE, 2019; ZORTRAX 2019).

Visually positive results were obtained from the renovation process. The chair was repaired in accordance with the original and gained back its former design look. Thus, the first step in making the chair reusable was completed. However, this result provides only visual satisfaction and does not give any information about the strength and load carrying values of the chair. The second step was to determine the strength and durability of the chair so that it can be reused safely. For this phase, various test methods specified in the standard numbered TS EN/ 16139 and named "Furniture - Strength, durability and safety - Requirements for non-domestic seating" of the Turkish Standards Institute (shortly known as TSE) were used. This standard derives its application principles from the standard EN 1728.

Test methods for safety, strength and durability in the standard TS EN/ 16139 are given in Table 1. This standard numbered TS EN/ 16139 specifies the safety, strength and durability requirements of all types of seating elements for nondomestic use by adults weighing less than $110 \mathrm{~kg}$ in weight, including workplace visitors' chairs. Within the scope of the study, the general operating criteria "L1" were selected to measure the 
safety, strength and durability requirements of the original chair and the renovated plywood chair (Table 1).

"Seat and chair back static load test" and "Seat shock test" were applied to both chairs according to the general working criteria of "L1". According to this criterion, the static load test of a seat and chair back involves simulating via testing devices the action of a person weighing $110 \mathrm{~kg}$ sitting on a chair 10 times, leaning on its back and standing back up. According to TS EN/ 16139 the test content, the load is applied 10 times on the seat element. For the "L1" test, the device loads a certain force on the seat. It waits for 30 seconds with each load and then unloads the chair. According to TS EN/ 16139 "Seat shock test", the loading cushion is placed on the seat for the test and the specified force is applied at a point on the center line of the seat at a distance of 100 $\mathrm{mm}$ from the front edge of the seat frame. In this test, a $25 \mathrm{~mm}$ thick foam layer was used as the seat loading cushion. The application principle of the loads is shown in Figure 2.

In this study, the original chair and a sample of the undamaged equivalent of the same chair were chosen in order to reach a conclusion about the load carrying values of the renovated plywood chair. This selected chair was compared with the renovated chair sample. The comparison was based on furniture strength tests determined by TS EN/ 16139 and it was aimed to compare the load carrying values of the chair samples with and without renovation.

Table 1 Safety, strength and durability tests standards

\begin{tabular}{|c|c|c|c|c|}
\hline \multicolumn{2}{|c|}{ Safety, strength and durability tests } & \multicolumn{2}{c|}{ Level } \\
\cline { 2 - 4 } & Reference & Loading & L1 \\
\hline \multirow{2}{*}{$\begin{array}{c}\text { Seat and chair back static } \\
\text { load test }\end{array}$} & $\begin{array}{c}\text { EN 1728:2012, } \\
\text { Art. } 6.4\end{array}$ & $\begin{array}{c}\text { Seat: force, } N \\
\text { Chair Back: force, } N \\
\text { "10 times" }\end{array}$ & $\begin{array}{c}1600 \\
560 \text { (min. force, } \\
410)\end{array}$ & $\begin{array}{c}\text { 2 } 000 \\
700 \text { (min. force, } \\
410)\end{array}$ \\
\hline Seat shock test & $\begin{array}{c}\text { EN 1728:2012, } \\
\text { Art. } 6.24\end{array}$ & $\begin{array}{c}\text { Drop Height, } \mathrm{mm} \\
\text { "10 times" }\end{array}$ & 240 & 300 \\
\hline
\end{tabular}

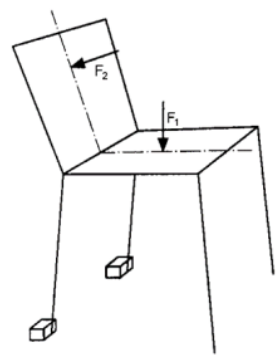

(a)

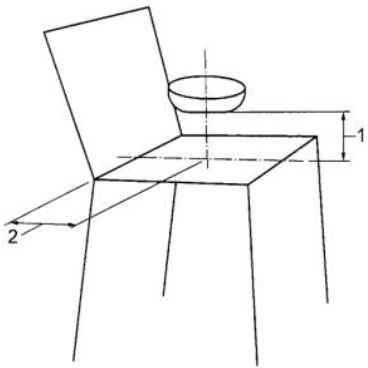

(b)

1- Drop height

2- Seat loading point according to template

Figure 2 (a) Seat and chair back static load test, (b) Seat shock test

\section{Results and Discussion}

In this study, the application of reverse engineering and additive manufacturing methods for furniture renovation was discussed. Reverse engineering is the process of acquiring information or obtaining data from any man-made item with the help of blue prints. Blue print is a photographic copy of the sketch of a building or machine. Reverse engineering is often used to obtain the missing information, ideas, or design philosophy when such information is not available (EILAM 2011; CAMBRIDGE DICTIONARY 2019) $)^{17,18}$. Additive manufacturing is a term more popularly known as $3 \mathrm{D}$ printer which is also known as rapid prototyping. This production method is used to create objects quickly and to produce print-outs in the form of simple models or prototypes (GIBSON et al., 2014) ${ }^{19}$.

The application part of the study consisted of combining reverse engineering approach and additive production systems. A damaged and unusable chair was chosen as a sample for the study (Figure 3-a,b,c). The body of this chair was made of plywood and the legs were made of metal. There was a housing under the body of this chair. A round plywood piece was attached to this housing by means of screws. This piece served to attach and fix the chair body to the feet. However, this joining piece had to be reproduced since it lost its function due to breaking apart. In this part of the study, backward design parameters of the damaged plywood material were obtained by using a 3D scanner supported reverse engineering approach in the Renovation process. The damaged piece was first scanned with the help of reverse engineering method using blue print technology. Then the data obtained from the scanner was converted to STL file. The damaged round plywood jointing apparatus was then reproduced with the help of a 3D printer in the office environment (Figure 3 and Figure 4/d).

In this study, for the plywood chair and the original chair to be renovated, it was decided to perform the static load test of the seat and chair back; which is specified in the TS EN/ 16139 standard covering the requirements of safety, strength and durability; according to the application principles of the general working criteria of "L1". In the application of this criterion, the original chair and the renovated plywood chair were fixed to the 
tester separately. The test was repeated for each chair. A $25 \mathrm{~mm}$ thick foam layer was placed on the seat and chair backrest before testing. After the relevant commands were entered into the computer, the test was started (Figure 5- a, b, c, d, e). The application of the loads is shown in Figure 5/a.

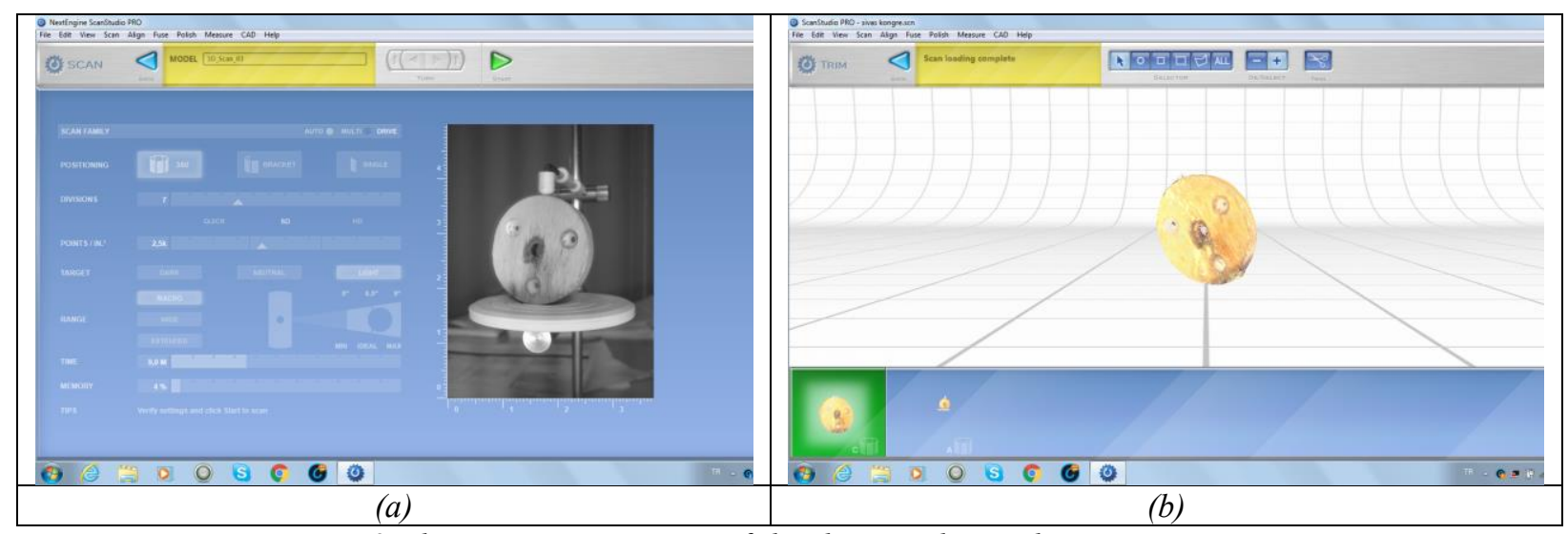

Figure 3 The scanning process of the damaged round jointing apparatus

(a) Firmware scan screen, (b) Cleaned final state of the point clouds of the scanned object

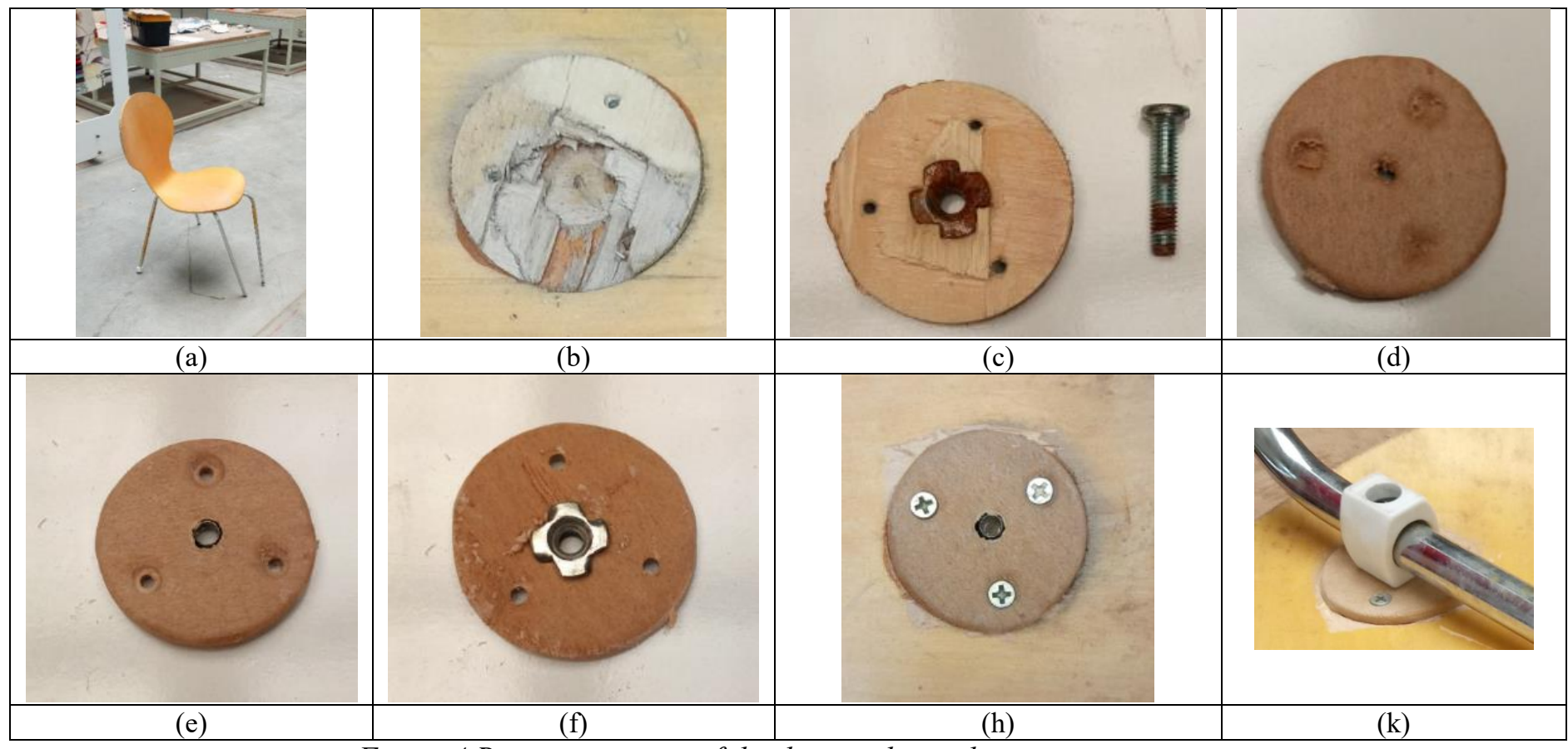

Figure 4 Revision process of the damaged round jointing apparatus

(a) Damaged chair, (b) Housing under the chair body, (c) Original jointing piece and nut, (d) New jointing piece produced with $3 D$ printer, (e and f) Inserting nuts and piercing screw holes into the new joining apparatus, (h) Installation of the new joining apparatus on the chair body, $(k)$ Mounting of the new joining apparatus to the leg

The load was applied 10 times on each chair. The device waited 30 seconds for each load on the chairs for testing and then pulled back from the chairs. As a result of the repetitive test process, both the original chair and the plywood chair which was renovated within the scope of the study had positive results in the test. In summary, both chairs underwent seat and chair back static load testing without any resulting deformation.

In the second phase of this study, seat shock test specified in TS EN/ 16139 standard covering safety, strength and durability requirements was carried out for both chairs. The original chair and the renovated plywood chair were subjected to this test according to the application principles of the general working criteria "L1". According to the application of the "L1" criteria, the original chair and the plywood chair that was renovated were fixed separately to the tester. The test was repeated for each chair. Two loading cushions (a $25 \mathrm{~mm}$ thick foam layer) were placed on the seat before the test was performed.

The position and drop height of the shock device were determined according to the position of the chair. The seat shock device was allowed to drop freely onto the seat from the specified height. According to the relevant standard, the test is repeated at a position where failure may occur, at a distance not less than 100 
$\mathrm{mm}$ from any edge of the seat. As a result, both chairs passed the seat shock test without any deformation (Figure 6).

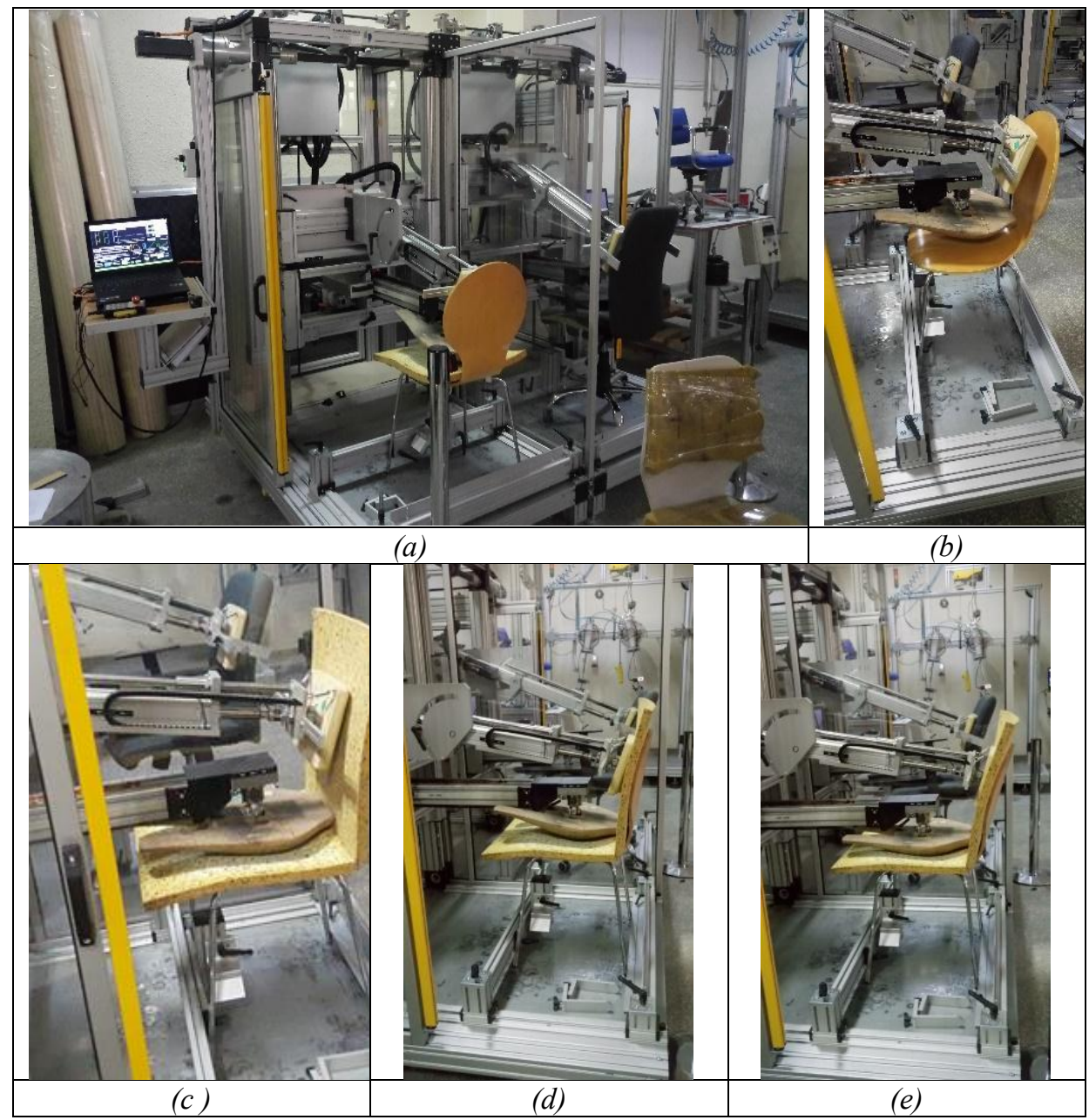

Figure 5 (a) Seat and chair back static load tester, (b) placement of chair in the tester, (c) placing of loading cushions, (d) initiation of the test, (e) application of the test to the seat and back

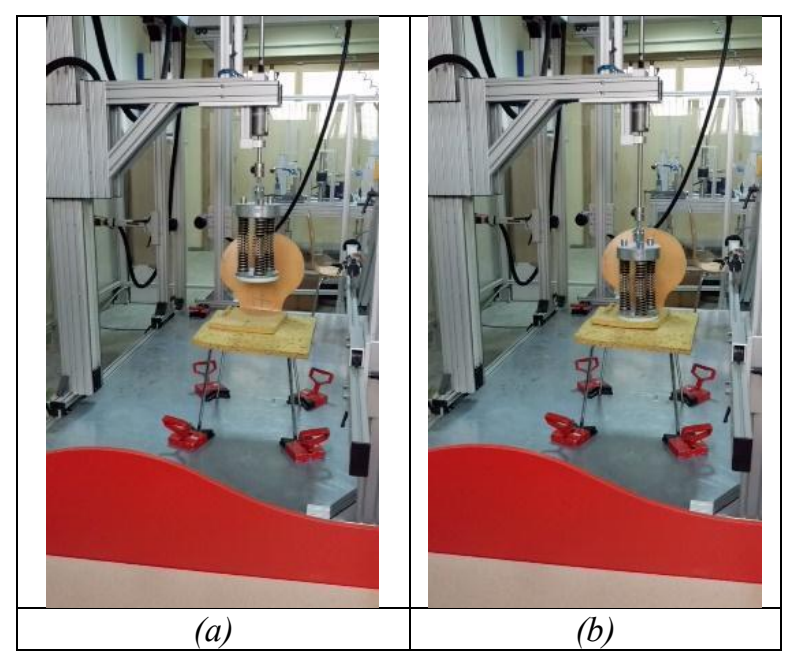

Figure 6 Seat shock test applied on chairs.

(a) before force is applied, (b) after force is applied

\section{Conclusions}

In these tests, in which TS EN/ 16139 standard was applied, it was determined that the renovated chair sample had the same mechanical properties as the original chair sample. The tests conducted have proved that the chair sample itself and all of its accessible parts produced by the renovation process will not cause any physical injury or harm to the user. According to the results 
of the tests, the following issues related to the renovated chair were determined:

- No fasteners or joints were broken,

- The joint that was designed to be fixed did not loosen,

- No significant deformation occurred in an element related to the structure of the chair body.

- The chair continues to perform its functions after the test loads are removed.

In addition to the servers, it was found that the joining apparatus, the details of which were determined with reverse engineering method and a copy of which was obtained with 3D printer, showed the same performance with the original material sample in the tests performed. In this case, it is concluded that the use of joining apparatus produced with $3 \mathrm{D}$ printers for domestic renovations will be beneficial for amateur users and those working in furniture renovation field.

\section{References}

AKKAS, G. The place of the reverse engineering approach in furniture renovation studies. International Symposium on Academic Studies in Science Engineering and Architecture Studies Abstract Book. Ankara, Turkey, 2019

https://kongre.akademikiletisim.com/files/fmsemp2019/Isms_Ab stract_Book.pdf

ANDAC GUZEL, T. Assessment of the use of additive production systems in the design and manufacture of furniture joining tools. International Symposium on Academic Studies in Science Engineering and Architecture Studies Abstract Book. Ankara, Turkey, 2019

https://kongre.akademikiletisim.com/files/fmsemp2019/Isms_Ab stract_Book.pdf

CAMBRIDGE DICTIONARY. Blue print.

https://dictionary.cambridge.org/tr/s\%C3\%B6zl\%C3\%BCk/ingil izce/blueprint. Available at: July 01st 2019.

CHENGMIN, Z.; MENGNAN, Y.; TAO, Z. Experimental study on three-dimensional shape mapping of complex furniture. EURASIP Journal on Image and Video Processing, v. 2018, n.1, p. 89. 2018.

DING, Z.; LIU, S.; LIAO, L.; L, ZHANG. A digital construction framework integrating building information modeling and reverse engineering technologies for renovation projects. Automation in Construction, v. 102, p. 45-58, 2019.

DUBRAVCIK, M.; KENDER, S. Application of reverse engineering techniques in mechanics system services. Procedia Engineering, v. 48, p. 96-104. 2012.

FONDEVİLA, A.; BOUSSEAU, A.; ROHMER, D.; HAHMANN, S.; M. P., CANI. Patterns from photograph: Reverse-engineering developable products. Computers and Graphics, 66: 4-13. 2017.

EILAM, E. Reversing: secrets of reverse engineering. Wiley, 2011.

GIBSON, I.; ROSEN, D. W.; STUCKER, B. Additive manufacturing technologies (Vol. 17). Springer, 2014.

KANG, H. D. Analysis of furniture design cases using 3D printing technique. The Journal of the Korea Contents Association. v. 15, n. 2, p. 177-186, 2015.

KASAL, A.; HASAN, EFE.; ERDIL, Y. Z. Determination of the strength of the ready to assemble sofa frames with finite element analysis. Journal of Polytechnic. v. 10, n. 4; p. 11 422 , https://dergipark.org.tr/tr/pub/politeknik/issue/33027/36719 4

JUNK, S.; MATT, R. New approach to introduction of 3D digital technologies in design education. Procedia Cirp. v., n. 36, p. 35-40, 2015.

NEXTENGINE. 3d-scanner. https://www.dospace.org/blog/introducing-our-nextengine3d-scanner/. Available at: July 08th 2019.

SAHIN, I.; SAHIN, T.; GOKCE, H. Reconstruction of damaged gears using reverse engineering approac. Duzce university journal of science and technology. v. 5, n. 2, p. 485-495, 2017.

https://dergipark.org.tr/tr/pub/dubited/issue/30665/307203

SCOPIGNO, R.; CIGNONI, P.; CALLIERI, M.; GANOVELLI, F.; IMPOCO, G.; PINGI, P.; PONCHIO, F. Using optically scanned 3D data in the restoration of Michelangelo's David. In Optical metrology for arts and multimedia, v. 5146, p. 4453, 2003.

THOMPSON, W. B.; OWEN, J. C.; GERMAIN, H. D. S.; STARK, S. R.; HENDERSON, T. C. Feature-based reverse engineering of mechanical parts. IEEE Transactions on robotics and automation, v. 15, n. 1, p. 57-66, 1999.

TS EN/ 16139: Furniture - Strength, durability and safety Requirements for non-domestic seating. Turkish Standard, Turkish Standard Intuition, Ankara, Turkey.

YANG, J.; HE, S.; LU, L. Binary Image Carving for 3D Printing. Computer-Aided Design. V. 114, p. 191-201, 2019.

ZORTRAX. Zortrax M200 3D printer.

https://zortrax.com/3d-printers/m200-plus/. Available at: July 05th.2019 